\title{
Trocas gasosas e teores de minerais no feijão-de-corda irrigado com água salina em diferentes estádios ${ }^{1}$
}

\author{
Antonia L. R. Neves ${ }^{2}$, Claudivan F. de Lacerda², Francisco V. A. Guimarães ${ }^{3}$, Enéas Gomes Filho \& Daniel R. C. Feitosa ${ }^{5}$
}

\begin{abstract}
RESUMO
Realizou-se este trabalho com o objetivo de estudar os efeitos da aplicação de água salina nos diferentes estádios de desenvolvimento de plantas de feijão-de-corda sobre as trocas gasosas, 0 crescimento e os teores de minerais. 0 experimento foi conduzido no campo e obedeceu o delineamento em blocos ao acaso, com cinco tratamentos e cinco repetições. 0 s tratamentos utilizados foram: T1 - água do poço (CEa de 0,8 dS m-1) durante todo o ciclo (controle); T2 - água salina (CEa de 5,0 dS $\mathrm{m}^{-1}$ ) durante todo 0 ciclo; T3, T4 e T5 - água salina de 0 a 22, de 23 a 42 e de 43 a 62 dias após o plantio (DAP), respectivamente. As plantas dos tratamentos $\mathrm{T3}, \mathrm{T} 4$ e T5 foram irrigadas com água do poço nas demais fases do ciclo. Realizaram-se, ao longo do ciclo da cultura, medições de trocas gasosas e se determinaram a produção de matéria seca e os teores de $\mathrm{Na}^{+}, \mathrm{Cl}^{-}, \mathrm{K}^{+}, \mathrm{Ca}^{2+}, \mathrm{N}$ e P. Os tratamentos T2 e T3 em relação ao T1 (controle), reduziram as taxas de fotossíntese e transpiração e as taxas de crescimento vegetativo e provocaram acúmulo, especialmente de $\mathrm{Na}^{+} \mathrm{e} \mathrm{Cl}$; porém se verificou, nas plantas do T3, recuperação de todas essas variáveis ao final do ciclo da cultura. As alterações no acúmulo de $\mathrm{Na}^{+}$e Cl- nas plantas dos tratamentos T4 e T5 não foram suficientes para provocar efeitos significativos nas trocas gasosas nem nas taxas de crescimento da cultura, em comparação com as plantas do T1.
\end{abstract}

Palavras-chave: Vigna unguiculata, salinidade, irrigação, nutrição mineral

\section{Gas exchange and mineral concentration in cowpea irrigated with saline water at different stages}

\begin{abstract}
The objective of this paper was to evaluate the effect of irrigation with saline water, applied at different development stages of cowpea, on gas exchange, growth and nutrient concentration. The experiment was set up in the field, in a completely randomized block design, with five treatments and five repetitions. The treatments studied were: $\mathrm{T} 1$ - Groundwater with electrical conductivity ( $\mathrm{ECW}$ ) of $0.8 \mathrm{dS} \mathrm{m^{-1 }}$ during the whole crop cycle (control); $T 2$ - saline water ( $E C W=5.0 \mathrm{dS} \mathrm{m}^{-1}$ ) during the whole crop cycle; $\mathrm{T} 3, \mathrm{~T} 4$ and $\mathrm{T} 5$ - saline water from 0 to $22^{\text {nd }}$ day after sowing (DAS), from the $23^{\text {rd }}$ to the $42^{\text {nd }}$ DAS and from the $43^{\text {rd }}$ to $62^{\text {nd }} D A S$, respectively. The plants of $T 3, T 4$ and $T 5$ were irrigated with groundwater in the remaining stages of the crop cycle. During the crop cycle, the gas exchange in leaves, dry mass production and mineral concentrations ( $\mathrm{Na}^{+}$, $\mathrm{Cl}^{-} \mathrm{K}^{+}, \mathrm{Ca}^{2+}, \mathrm{N}$ and $\mathrm{P}$ ) were determined. The treatments $\mathrm{T} 2$ and $\mathrm{T} 3$, as compared to $\mathrm{T} 1$, reduced the net photosynthesis and transpiration, the absolute and relative growth rates, and caused an increase in $\mathrm{Na}^{+}$and $\mathrm{Cl}^{-}$concentrations. However, in the plants belonging to the $\mathrm{T} 3$ treatment, recovery was observed for all these variables. The changes in $\mathrm{Na}^{+}$and $\mathrm{Cl}^{-}$concentration in plants of $\mathrm{T} 4$ and $\mathrm{T} 5$ were not sufficient to provoke significant effects in gas exchange and on plant growth.
\end{abstract}

Key words: Vigna unguiculata, salinity, irrigation, mineral nutrition

\footnotetext{
1 Parte da Dissertação de Mestrado da primeira autora, apresentada ao Departamento de Engenharia Agrícola da Universidade Federal do Ceará 2 DENA/UFC, Campus do Pici, Bloco 804, CEP: 60.455-970, Fortaleza, CE. Fone: (85) 3366-9756. E-mail: leilaneves7@hotmail.com; cfeitosa@ufc.br 3 Departamento de Ciências do Solo/UFC. Fone: (85) 3366-9689. E-mail: valderez@ufc.br

${ }^{4}$ Departamento de Bioquímica e Biologia Vegetal/UFC. Fone: (85) 3366-9829. E-mail: egomesf@ufc.br

${ }^{5}$ Bolsista de Iniciação Científica. Estudante de Graduação em Agronomia/UFC. Fone: (85) 3366-9756. E-mail: daniel.feitosa@yahoo.com.br
} 


\section{INTRODUÇÃO}

O estresse salino inibe o crescimento das plantas em razão de reduzir o potencial osmótico da solução do solo, restringindo a disponibilidade de água e/ou pela acumulação excessiva de íons nos tecidos vegetais, podendo ocasionar toxicidade iônica, desequilíbrio nutricional, ou ambos; no entanto, o grau de severidade com que esses componentes influenciam o desenvolvimento das plantas é dependente de muitos fatores, como, espécie vegetal, cultivar, estádio fenológico, composição salina do meio, intensidade e duração do estresse e das condições edafoclimáticas e, ainda, manejo da irrigação (Yeo, 1999; Silva et al., 2003; Gheyi et al., 2005).

As concentrações de sais que restringem o crescimento do feijão-de-corda variam entre os cultivares e parecem depender da composição iônica do meio (Dantas et al., 2002; Costa et al., 2003; Wilson et al., 2006a). A redução no crescimento de plantas de feijão-de-corda tem sido associada, em grande parte, ao acúmulo de íons potencialmente tóxicos, particularmente $\mathrm{Na}^{+} \mathrm{e} \mathrm{Cl}^{-}$(Silva et al., 2003; Assis Júnior et al., 2007). De modo geral, o acúmulo de $\mathrm{Cl}^{-}$ é maior que o de $\mathrm{Na}^{+}$nessa cultura, sobretudo nos limbos foliares (Assis Júnior et al., 2007), e isso parece contribuir para o aumento no grau de suculência de suas folhas (Costa et al., 2003; Lacerda et al., 2006). De acordo com alguns autores, no entanto, o elevado acúmulo de $\mathrm{Cl}^{-}$nas folhas associado, possivelmente, à falta de outros mecanismos eficientes de proteção contribuiu, pelo menos em parte, para a redução no crescimento do feijão-de-corda sob estresse salino (Trindade et al., 2006).

Associado ao acúmulo total de sais no solo, o estresse osmótico reduz a disponibilidade de água para os vegetais e pode, em consequência, afetar as trocas gasosas e o crescimento das plantas (Bezerra et al., 2003); além disso, nas espécies sensíveis o acúmulo de sódio e de cloreto pode produzir necrose nos tecidos foliares e acelerar a senescência de folhas maduras, fatores que reduzem a área destinada à fotossíntese (Munns, 2002; Bezerra et al., 2005); deste modo, se os efeitos osmóticos e específicos dos íons associados com a salinidade ultrapassam o limite de tolerância da planta, ocorrem distúrbios funcionais e injúrias, caso em que a fotossíntese é limitada não só pelo fechamento estomático mas, também, pelo efeito dos sais nos cloroplastos. De acordo com Assis Júnior et al. (2007) e Wilson et al. (2006b), a redução na produtividade do feijão-de-corda provocada pela salinidade se deve, em parte, à limitação na assimilação líquida de carbono pelos tecidos foliares. Esses autores demonstraram que as reduções nas taxas de fotossíntese foram devidas ao fechamento parcial dos estômatos nas plantas irrigadas com águas salinas, não sendo descartados, no entanto, os efeitos associados à toxidez causada pelo excesso de $\mathrm{Na}^{+}$e $\mathrm{Cl}^{-}$nos tecidos foliares dessas plantas.

Neste trabalho se estudaram as trocas gasosas, as taxas de crescimento e os teores de $\mathrm{Na}^{+}, \mathrm{Cl}^{-}, \mathrm{K}^{+}, \mathrm{Ca}^{2+}, \mathrm{P}$ e $\mathrm{N}$ nas folhas e caules de plantas de feijão-de-corda em função da irrigação com água salina aplicada nos diferentes estádios de desenvolvimento.

\section{MATERIAL E MÉTODOS}

O experimento foi conduzido no campo, em uma área de Argissolo Vermelho Amarelo, pertencente ao Laboratório de Hidráulica e Irrigação da Universidade Federal do Ceará, Campus do Pici, em Fortaleza ( $3^{\circ} 45^{\prime} \mathrm{S} ; 38^{\circ} 33^{\prime} \mathrm{W}$ e altitude de 19 m em relação ao nível do mar). Segundo a classificação de Köppen, a área do experimento está localizada em uma região de clima Aw'.

Uilizou-se sementes de feijão-de-corda (Vigna unguiculata (L) Walp.) cultivar EPACE 10. Os tratamentos empregados foram os seguintes: T1 - plantas irrigadas com água do poço com condutividade elétrica (CEa) em torno de $0,8 \mathrm{dS}$ $\mathrm{m}^{-1}$ durante todo o ciclo (controle); T2 - água salina com CEa de 5,0 dS m ${ }^{-1}$, com aplicação iniciada após a emergência e permanecendo até o final do ciclo; T3 - água salina com CEa de $5,0 \mathrm{dS} \mathrm{m}^{-1}$, do início da semeadura até 22 dias após o plantio (DAP), correspondendo às fases de germinação e crescimento inicial, e água do poço no restante do ciclo; T4 - água salina com CEa de 5,0 dS m${ }^{-1}$, aplicada de 23 a 42 DAP (fase de intenso crescimento vegetativo até a pré floração), e água do poço nas demais fases do ciclo e T5 - água do poço da semeadura até 42 DAP e água salina (CEa de 5,0 dS m$~^{-1}$ ) aplicada a partir de 43 DAP (floração e frutificação).

Para o preparo das soluções salinas foram utilizados os sais de $\mathrm{NaCl}, \mathrm{CaCl}_{2} \cdot 2 \mathrm{H}_{2} \mathrm{O}$ e $\mathrm{MgCl}_{2} \cdot 6 \mathrm{H}_{2} \mathrm{O}$, na proporção equivalente de 7:2:1, obedecendo-se à relação entre $\mathrm{CEa}$ e concentração $\left(\right.$ mmol $\left._{c} L^{-1}=C E x 10\right)$, extraída de Rhoades et al. (2000). A água foi aplicada em sulcos nivelados e fechados e as lâminas de irrigação definidas com base nos valores de evapotranspiração de referência (ETo) obtidas através do Tanque Classe A e dos coeficientes da cultura $(\mathrm{Kc})$ recomendados por Souza et al. (2005), adicionando-se a fração de lixiviação de $13 \%$ calculada de acordo com Ayers \& Westcot (1999). O turno de rega usado foi de três dias, sendo que as plantas de todos os tratamentos foram irrigadas até 62 DAP. A lâmina total de água aplicada em todos os tratamentos ao longo do ciclo, foi de 326,3 mm. A adubação das plantas seguiu a recomendação de Fernandes (1993).

Utilizou-se o delineamento experimental em blocos ao acaso, com cinco tratamentos e cinco repetições, sendo que cada parcela apresentou o comprimento de 5,0 m com 3,2 m de largura, com quatro linhas de plantio. As plantas foram cultivadas em espaçamento de $0,8 \mathrm{~m}$ entre linhas e $0,3 \mathrm{~m}$ entre plantas, com duas plantas por cova.

Efetuaram-se, aos 22, 42 e 61 DAP, medições das trocas gasosas (taxa de fotossíntese líquida, taxa de transpiração e condutância estomática) em folhas completamente maduras e se determinaram as medições por meio de um analisador de gás no infravermelho (IRGA, ADC System), cujas leituras foram realizadas entre 9:00 e 11:00 horas sob condições de umidade relativa do ar, temperatura e radiação ambientais.

Por ocasião do desbaste (8 DAP) e aos 23, 43 e 63 DAP, grupos de plantas (20 plantas no desbaste, quatro nas coletas intermediárias e oito na coleta final), em competição plena em cada tratamento, foram coletados separando-se folhas (limbos foliares) e hastes (caule e pecíolos). Após a obtenção da massa fresca, amostras homogêneas de aproxima- 
damente $200 \mathrm{~g}$ de folhas e $200 \mathrm{~g}$ de hastes (caule e pecíolos) foram acondicionadas em sacos de papel e, após secagem em estufa a $60{ }^{\circ} \mathrm{C}$, pesadas para obtenção da matéria seca. Obtevese a produção de matéria seca por planta multiplicando-se a massa fresca pelo teor de matéria seca das diferentes partes da planta e com os dados de produção de matéria seca das partes vegetativas, calcularam-se a partição de carbono entre folhas e hastes, ao longo do ciclo da cultura, as taxas de crescimento absoluto (TCA) e as taxas de crescimento relativo (TCR) da parte aérea, segundo metodologia de Benincasa (1988).

As amostras secas (limbos foliares e hastes) foram trituradas separadamente em moinho tipo Wiley, acondicionadas em sacos de papel e devidamente identificadas sendo este, portanto, o material utilizado nas determinações dos teores dos elementos minerais ( $\mathrm{Na}, \mathrm{Cl}, \mathrm{K}, \mathrm{Ca}, \mathrm{P}$ e $\mathrm{N}$ ), de acordo com Malavolta et al. (1997).

Os resultados foram submetidos a análise de variância, tendo-se realizado a comparação entre médias pelo teste de Tukey a 5\% de probabilidade utilizando-se, como ferramenta de apoio, o programa SAEG/UFV, e os dados obtidos ao longo do tempo foram expressos pela média \pm erro padrão.

\section{RESULTADOS E DISCUSSÃO}

\section{Trocas gasosas}

A aplicação contínua de água com CEa de $5 \mathrm{dS} \mathrm{m}^{-1}$ (T2) reduziu a condutância estomática (Figura 1A), a taxa de transpiração (Figura 1B) e a taxa fotossintética (Figura 1C) em praticamente todas as medições realizadas, em relação à aplicação de água do poço (controle). Os efeitos da salinidade foram mais expressivos sobre a condutância estomática, o que está de acordo com os resultados obtidos por outros autores (Assis Júnior et al., 2007). Este fechamento parcial dos estômatos pode ser decorrente da redução da condutividade hidráulica do sistema radicular, em função do aumento da suberização e lignificação dos tecidos vasculares das raízes de plantas sob estresse salino (Peyrano et al., 1997).

A redução na taxa fotossintética (Figura 1C), por sua vez, pode ser devida ao fechamento parcial dos estômatos, associado aos efeitos osmóticos da salinidade (Guimarães, 2005; Bezerra et al., 2005; Wilson et al., 2006b). De acordo com Kurban et al. (1999), no entanto, as reduções nas taxas fotossintéticas pelo estresse salino podem estar mais relacionadas com os danos no aparelho fotossintético e/ou no sistema enzimático de fixação do $\mathrm{CO}_{2}$, causadas pela toxidez iônica sobre o metabolismo do que, propriamente, com as limitações estomáticas.

A aplicação de água salina na fase inicial (T3) provocou redução das trocas gasosas mas somente na primeira medição (Figura 1); ressalta-se, em relação às plantas do T3 que, ao final do ciclo, elas apresentaram maiores valores da taxa de fotossíntese o que se deve ao fato de suas folhas ainda se apresentarem mais verdes que aquelas dos outros tratamentos. No caso dos tratamentos T4 e T5 a aplicação de água salina não provocou reduções significativas nas trocas gasosas das plantas, exceto no final do ciclo, quando o proces-
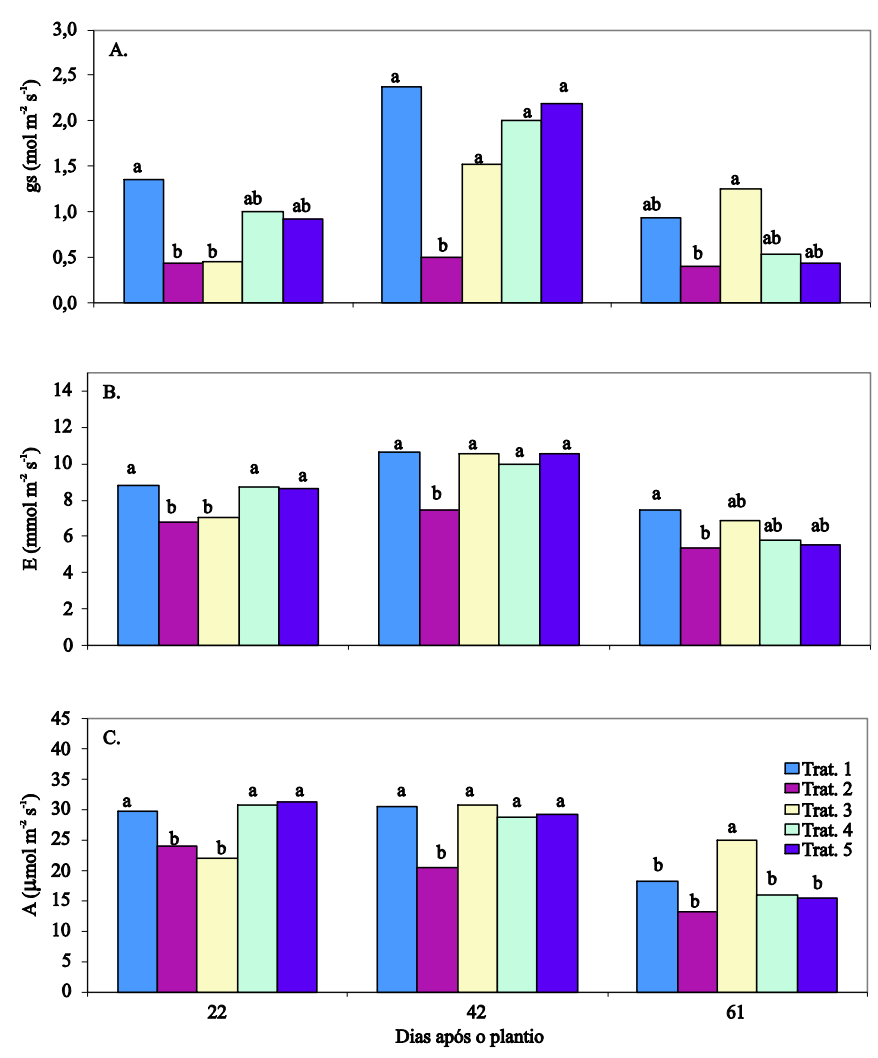

Figura 1. (A) Condutância estomática $\left(g_{s}\right)$; $(B)$ transpiração $(E)$ e $(C)$ taxa de fotossíntese líquida (A), em folhas maduras de plantas de feijão-de-corda em função dos tratamentos (T1 a T5) e da época de medição (dias após o plantio). Valores com as mesmas letras, para cada época, não diferem estatisticamente pelo teste de Tukey a $5 \%$

so de senescência das folhas foi intensificado visto que a colheita de vagens nas plantas desses tratamentos já se havia iniciado aos 58 DAP, notadamente no T4.

\section{Taxas de crescimento e partição de matéria seca}

As estimativas das taxas de crescimento absoluto (TCA) e relativo (TCR) mostram o comportamento das plantas em função da irrigação com água salina nos diferentes estádios de desenvolvimento da cultura (Tabela 1). Nos dois primeiros períodos as plantas dos tratamentos T2 e T3 apresentaram as menores TCA e TCR (Tabela 1) porém na fase final do ciclo os valores do T2 não diferiram daqueles observados nos tratamentos T1 (controle), T4 e T5. Por outro lado, as plantas do T3 mostraram comportamento diferente das demais, apresentando as menores taxas de crescimento na fase inicial do ciclo e as maiores na fase final. Esses resultados não só refletem os efeitos da salinidade da água de irrigação na fase inicial e o processo de recuperação do crescimento quando as plantas passaram a ser irrigadas com água de baixa salinidade, mas também deixam claro um retardamento no crescimento das plantas do T3, o que justifica suas maiores taxas de fotossíntese no final do ciclo (Figura 1C).

A limitação na assimilação líquida de carbono pelos tecidos foliares (Figura 1C) pode ter contribuído para a redução no crescimento das plantas do T2, conforme sugerem outros autores (Chartzoulakis \& Loupassaki, 1997; Munns, 2002; Wilson et al., 2006b; Assis Júnior et al., 2007); entretanto, as 
Tabela 1. Taxa de crescimento absoluto (TCA) e taxa de crescimento relativo (TCR) de plantas de feijão-de-corda irrigadas com água salina em diferentes estádios de desenvolvimento

\begin{tabular}{|c|c|c|c|c|c|c|}
\hline \multirow{2}{*}{ Tratamentos } & \multicolumn{3}{|c|}{ TCA $\left(g\right.$ dia $\left.^{-1}\right)$} & \multicolumn{3}{|c|}{ TCR $\left(\mathrm{g} \mathrm{g}^{-1} \mathrm{dia}^{-1}\right)$} \\
\hline & 8 a 23 dias & 23 a 43 dias & 43 a 63 dias & 8 a 23 dias & 23 a 43 dias & 43 a 63 dias \\
\hline $\mathrm{T} 1$ & $0,148 \mathrm{a}$ & $0,909 a$ & $0,566 \mathrm{~b}$ & $0,179 b$ & $0,112 \mathrm{a}$ & $0,019 b$ \\
\hline $\mathrm{T} 2$ & $0,102 b$ & $0,425 b$ & $0,338 \mathrm{~b}$ & $0,162 c$ & $0,090 \mathrm{~b}$ & $0,026 \mathrm{~b}$ \\
\hline T3 & $0,084 b$ & $0,569 \mathrm{~b}$ & $0,900 \mathrm{a}$ & $0,154 \mathrm{c}$ & $0,111 \mathrm{a}$ & $0,046 a$ \\
\hline $\mathrm{T} 4$ & $0,165 a$ & $0,883 a$ & $0,465 \mathrm{~b}$ & $0,190 a b$ & $0,102 \mathrm{a}$ & $0,020 \mathrm{~b}$ \\
\hline $\mathrm{T} 5$ & $0,177 \mathrm{a}$ & $1,020 \mathrm{a}$ & $0,366 \mathrm{~b}$ & $0,196 \mathrm{a}$ & $0,106 \mathrm{a}$ & $0,011 b$ \\
\hline
\end{tabular}

Médias nas colunas com as mesmas letras não diferem estatisticamente pelo teste de Tukey a $5 \%$. $n=5$

reduções nas taxas de fotossíntese foram bem menos expressivas do que aquelas observadas no crescimento vegetativo, indicando que a redução na expansão celular antecede a inibição do processo fotossintético pela salinidade (Bezerra et al., 2003; Bezerra et al., 2005; Lacerda et al., 2006; Assis Júnior et al., 2007).

$\mathrm{Na}$ Figura 2 se encontram os valores da percentagem da matéria seca foliar (MSFO) e de hastes (MSHA) do feijão-decorda, ao longo do ciclo, sob diferentes tratamentos. Observando-se os resultados da partição de matéria seca ao longo do ciclo, nota-se diminuição de MSFO e aumento na proporção de MSHA em todos os tratamentos porém os tratamentos T2 e T3 apresentaram, de modo geral, maior proporção de folhas e menor de hastes em relação aos tratamentos T1 (controle), T4 e T5, sugerindo a existência de uma alteração na proporção entre fontes e drenos; este aumento na proporção entre folhas e caules (fontes e drenos), especialmente no T2, poderia ser interpretado como resultado da aclimatação ao estresse salino e, também, contribuir para compensar o aumento no custo metabólico necessário para a aclimatação da planta ao estresse imposto (Munns, 2002; Mendes et al., 2005; Lacerda et al., 2006).

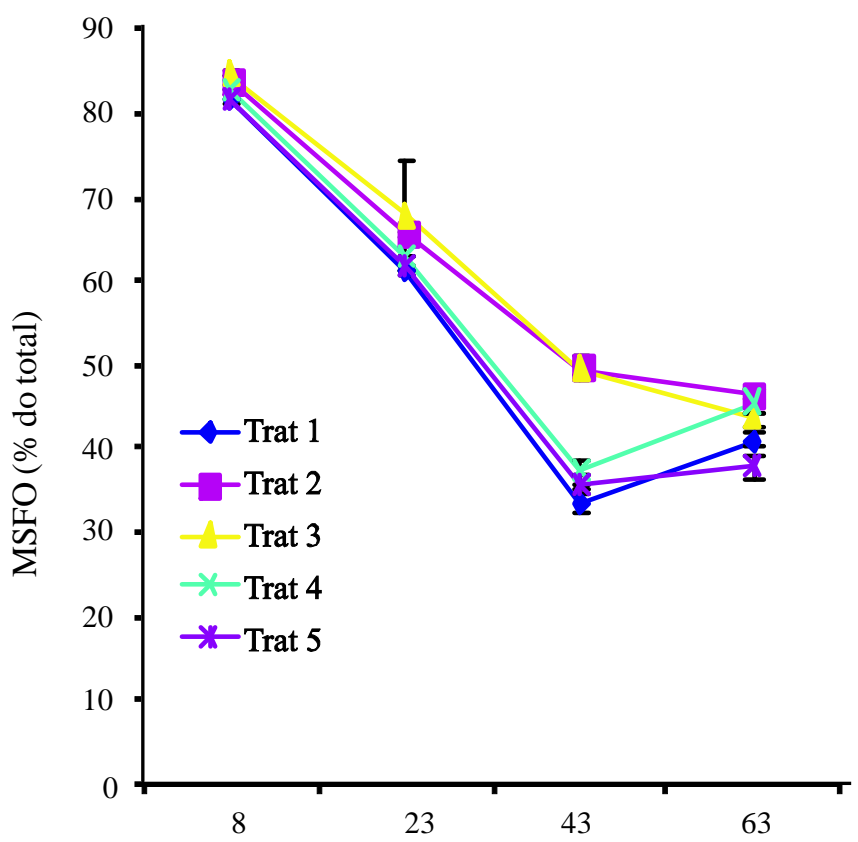

\section{Teores de íons}

A análise da Figura 3 mostra que os teores de $\mathrm{Na}^{+} \mathrm{e} \mathrm{Cl}^{-}$ variaram ao longo do ciclo da cultura refletindo a presença desses íons na água de irrigação e as taxas de crescimento da cultura; aos 8 e aos 23 DAP, os teores de $\mathrm{Na}^{+}$foram maiores nos tratamentos $\mathrm{T} 2$ e $\mathrm{T} 3$, notadamente nas hastes, em relação aos demais tratamentos, visto que neste período os mesmos estavam recebendo água salina (Figuras 3A e B). Os teores de $\mathrm{Na}^{+}$foram maiores nas hastes, refletindo o mecanismo de retenção desse íon nas plantas de feijão-de-corda, evitando seu acúmulo excessivo nos tecidos foliares (Trindade et al., 2006). Os elevados teores de $\mathrm{Na}^{+}$nas plantas do $\mathrm{T} 2$ certamente contribuíram para a inibição das taxas de fotossíntese (Figura 1C) e de crescimento (Tabela 1).

As plantas do T3 apresentaram os maiores teores de $\mathrm{Na}^{+}$ nas duas primeiras coletas porém, a partir dos 43 DAP, observou-se redução nos teores desse íon, refletindo a substituição da fonte de água na irrigação dessas plantas; referida redução, no entanto, foi maior nas hastes que nas folhas, indicando que parte do sódio acumulado nas hastes foi transportado para as folhas novas através do fluxo

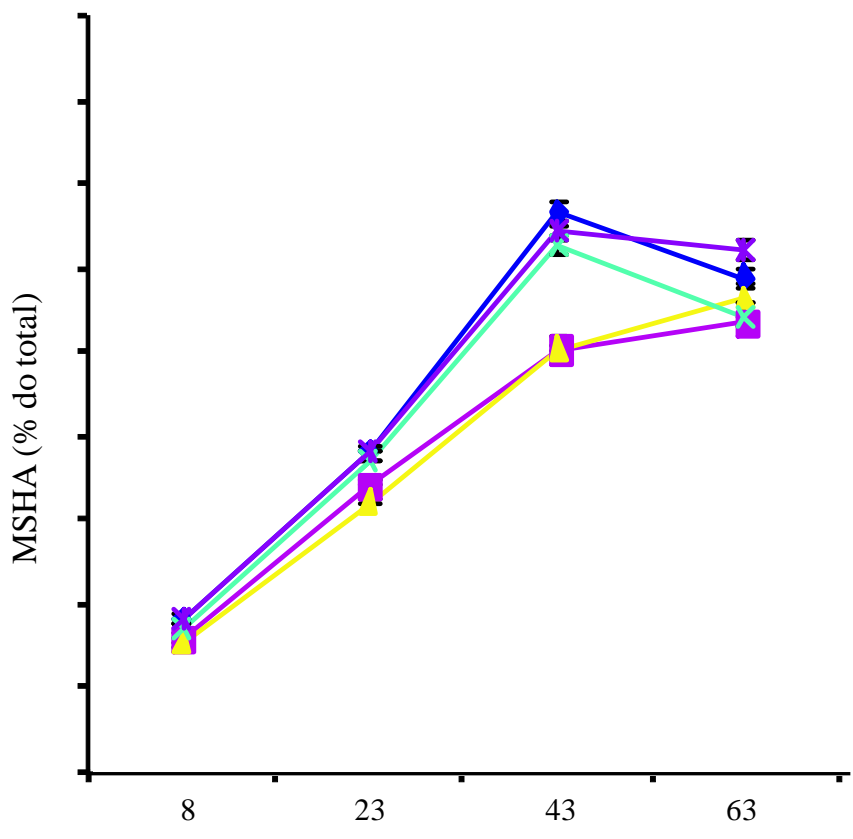

Dias após o plantio

Figura 2. Distribuição percentual da matéria seca foliar (M SFO) e matéria seca das hastes (M SHA) de plantas de feijão-de-corda, irrigadas com água salina em diferentes estádios de desenvolvimento. OBS.: Os valores são expressos como percentagem da matéria seca total da parte aérea vegetativa. 

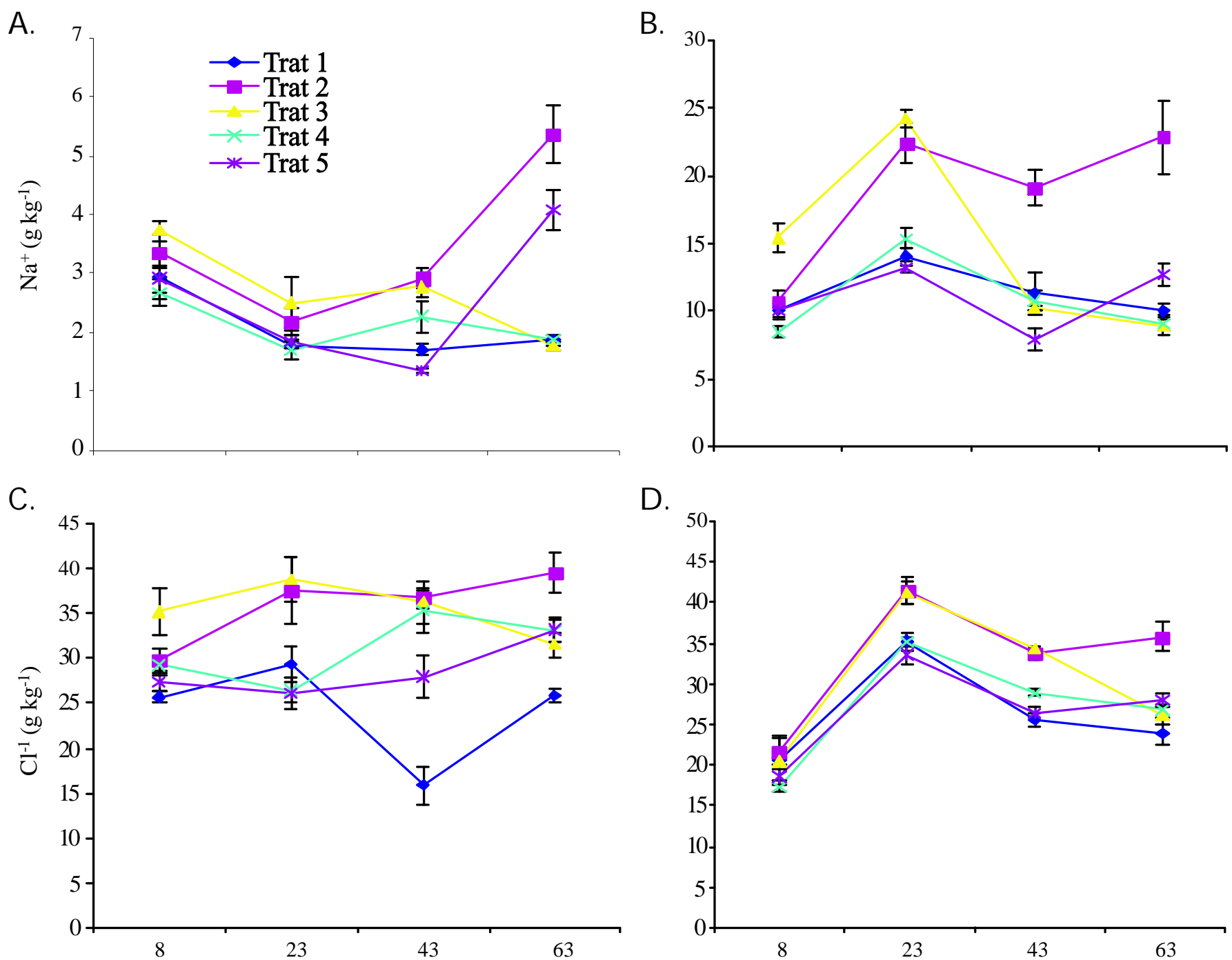

D.

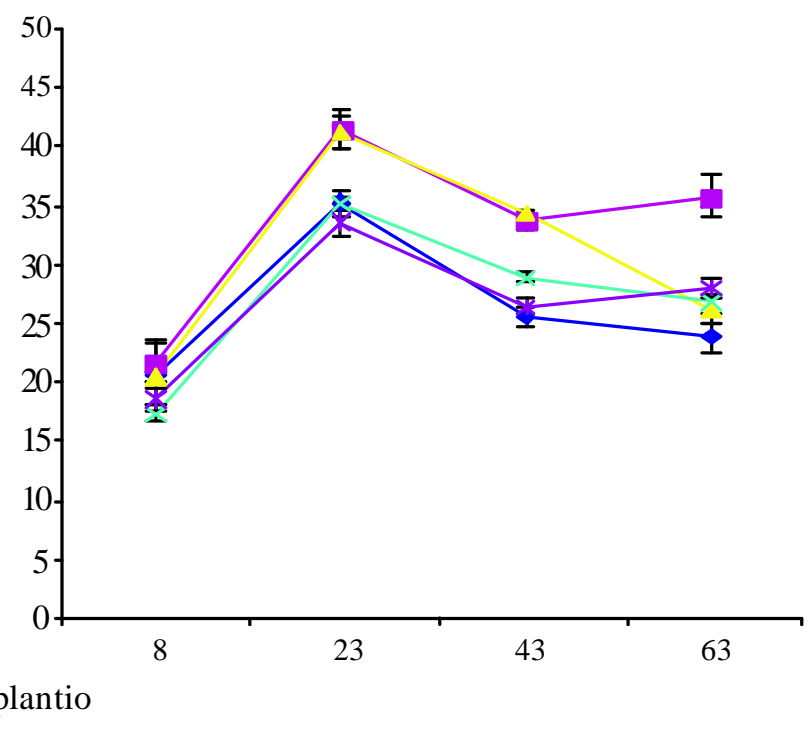

Figura 3. Teores de $\mathrm{Na}^{+}$e $\mathrm{Cl}$; em fol has ( $\mathrm{A}$ e C) e hastes ( $\mathrm{B}$ e D) de plantas de feijão-de-corda irrigadas com água salina em diferentes estádios de desenvolvimento, as barras representam o erro padrão da média. $n=5$

transpiratório. A redução no teor de $\mathrm{Na}^{+}$foi acompanhada pela recuperação das plantas desse tratamento, as quais apresentaram elevadas taxas de crescimento na fase final do ciclo (Tabela 1).

Os aumentos nos teores de $\mathrm{Na}^{+}$foram pouco expressivos no T4, o que pode ser justificado pelo fato das plantas terem apresentado elevadas taxas de crescimento (Tabela 1) durante o período em que foram irrigadas com água salina o que, certamente, promoveu a diluição dos íons na planta. Aumentos expressivos foram verificados ao final do ciclo nos tratamentos T2 e T5 devido em parte, à redução nas taxas de crescimento vegetativo (Tabela 1) e, provavelmente, ao aumento na extração de íons do solo por fluxo em massa durante esta fase.

De modo geral, os teores de cloreto (Figura 3C e D) apresentaram comportamentos similares aos de sódio (Figura 3A e B); os teores de cloreto, no entanto, foram bem mais elevados que os de $\mathrm{Na}^{+}$, o que se deve, em parte, ao fato do cloreto ter sido aplicado por ocasião da adubação potássica em todos os tratamentos. Resultados semelhantes obtiveram Trindade et al. (2006) e Assis Júnior et al. (2007). Os teores de $\mathrm{Cl}^{-}$após os 43 DAP foram maiores nas plantas irrigadas com água salina após a emergência (T2), contribuindo para a redução no crescimento das plantas desse tratamento. Foi observado, também, teores elevados de $\mathrm{Cl}^{-}$nas plantas do T3 nas duas primeiras coletas, ocorrendo um decréscimo no teor desse íon nos estádios posteriores. Nas hastes houve um acúmulo de $\mathrm{Cl}^{-}$aos 8 DAP muito maior que nas folhas, destacando um mecanismo de retenção deste íon nesses órgãos. Também se observaram variações nos teores desse íon ao longo do ciclo da cultura nos diversos tratamentos, refletindo a mobilidade do $\mathrm{Cl}^{-}$nos fluxos xilemático e floemático (Marschner, 1995).

Os teores foliares de $\mathrm{Ca}^{2+}$ aumentaram ao longo do ciclo da cultura, refletindo o tempo de acumulação pelo fluxo transpiratório e a baixa mobilidade desse nutriente na planta (Figura 4A). Os teores foram similares aos encontrados por Guimarães (2005) e Assis Júnior et al. (2007), porém inferiores aos relatados por 
A.

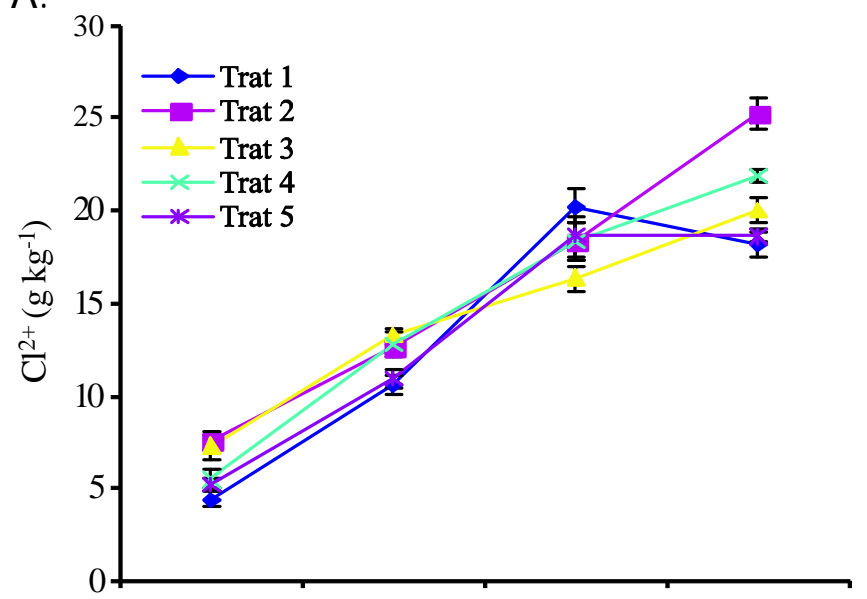

C.

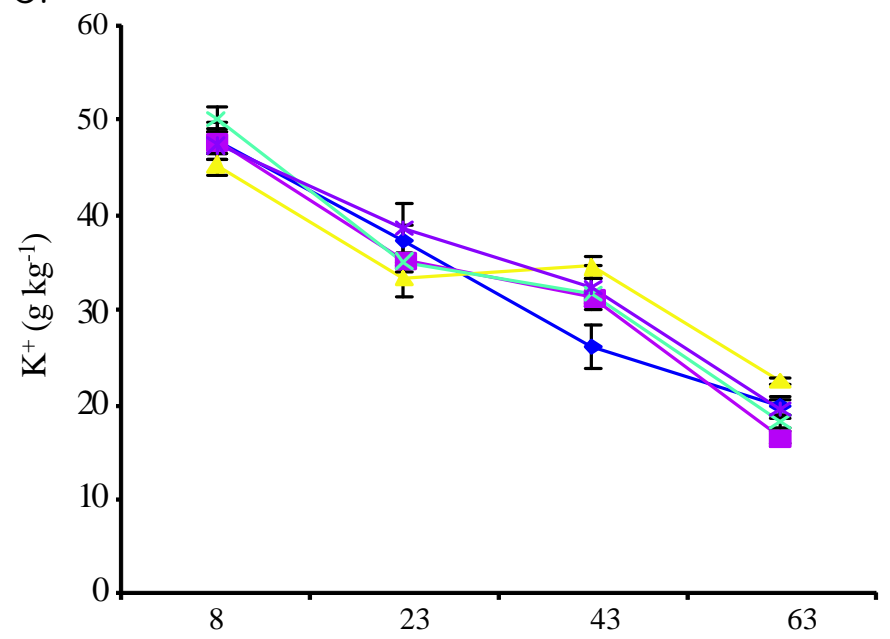

B.

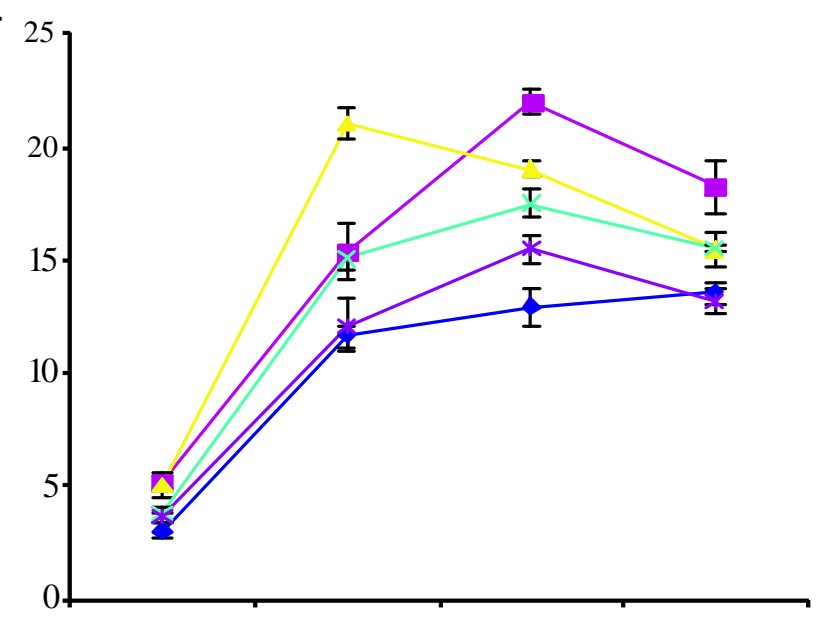

D.

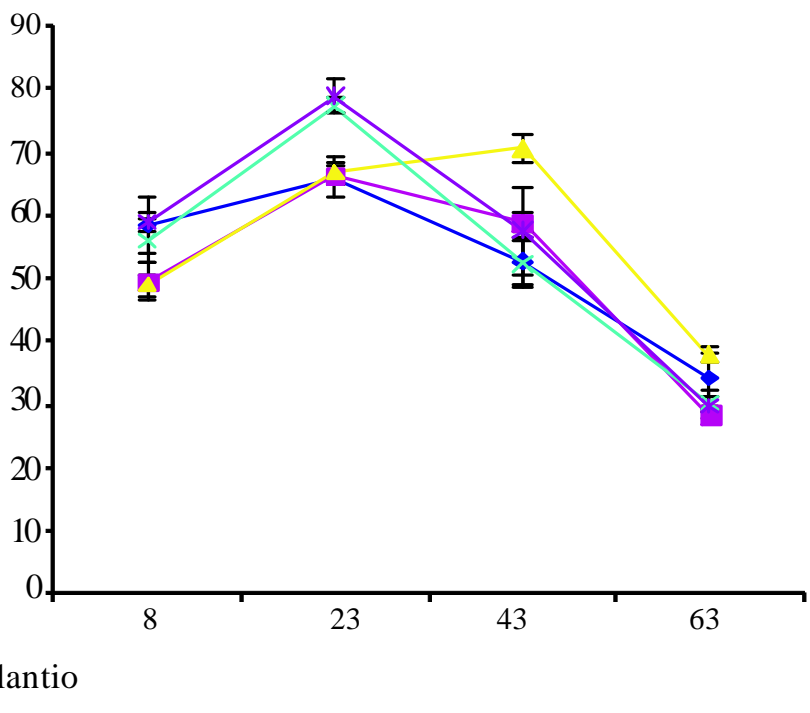

Figura 4. Teores de $\mathrm{Ca}^{2+}$ e $\mathrm{K}^{+}$em folhas ( $\mathrm{A}$ e $\mathrm{C}$ ) e hastes ( $\mathrm{B}$ e D) de plantas de feijão-de-corda irrigadas com água salina em diferentes estádios de desenvolvimento; as barras verticais representam 0 erro padrão da média. $n=5$

outros autores (Melo et al., 2005). De modo geral, os teores de $\mathrm{Ca}^{2+}$ nas folhas foram superiores aos das hastes (Figura $4 \mathrm{~A} \mathrm{e}$ B), resultado também encontrado por Sousa et al. (2007) em plantas de feijão-de-corda cv Pitiúba, submetidas a estresse salino. Ao final do ciclo os teores de $\mathrm{Ca}^{2+}$ (Figura 4A e B) foram maiores nas plantas irrigadas continuamente com água salina após a emergência (T2) e menores nas plantas irrigadas com água do poço T1 (controle) e T5.

Estudos em solos com problema de salinidade têm mostrado que o aumento na concentração de $\mathrm{Na}^{+}$é acompanhado pelo decréscimo na concentração de $\mathrm{Ca}^{2+}$ trocável, resultando em um desequilíbrio iônico, que pode afetar o crescimento das plantas, porém o feijão-de-corda parece manter a absorção de $\mathrm{Ca}^{2+}$, mesmo quando a concentração de $\mathrm{Na}^{+}$aumenta no ambiente radicular, conforme tem sido observado também por outros autores (Silva et al., 2003). É importante destacar que o $\mathrm{Ca}^{2+}$ estava presente em maiores concentrações na água rica em sais, o que justifica a acumulação desse nutriente nas plantas mais expostas à aplicação dessa fonte de água. Os teores de $\mathrm{Ca}^{2+}$ nas hastes decresceram no final do ciclo (Figura 4B), particularmente nas plantas do tratamento T3 devido, em parte, ao intenso crescimento das plantas do tratamento neste período o que, sem dúvida, provocou um efeito de diluição.

Os teores foliares de potássio decresceram ao longo do ciclo, em todos os tratamentos (Figura 4C e D) o que se deve, em parte, aos efeitos de diluição e à mobilização desse nutriente para os drenos reprodutivos da planta. Nas hastes houve um aumento dos 8 aos 23 DAP, decrescendo nas demais fases do desenvolvimento da cultura. Ao final do ciclo os teores de $\mathrm{K}^{+}$foram maiores nas plantas do tratamento $\mathrm{T} 3$, fato explicado pelo retardo no crescimento (Tabela 1) e desenvolvimento dessas plantas. Os teores de potássio variaram ao longo do ciclo da cultura sendo que, em média, os valores foram superiores aos encontrados por Assis Júnior et al. (2007), porém similares aos encontrados por Costa et al. (2003) e Guimarães (2005). Os valores encontrados nas folhas foram também superiores ao nível considerado crítico para o feijão-de-corda durante as fases de crescimento e floração da cultura (Melo et al., 2005).

A aplicação contínua de água salina (T2) praticamente não influenciou no acúmulo do íon $\mathrm{K}^{+}$nas folhas (Figura 4C), re- 
A.

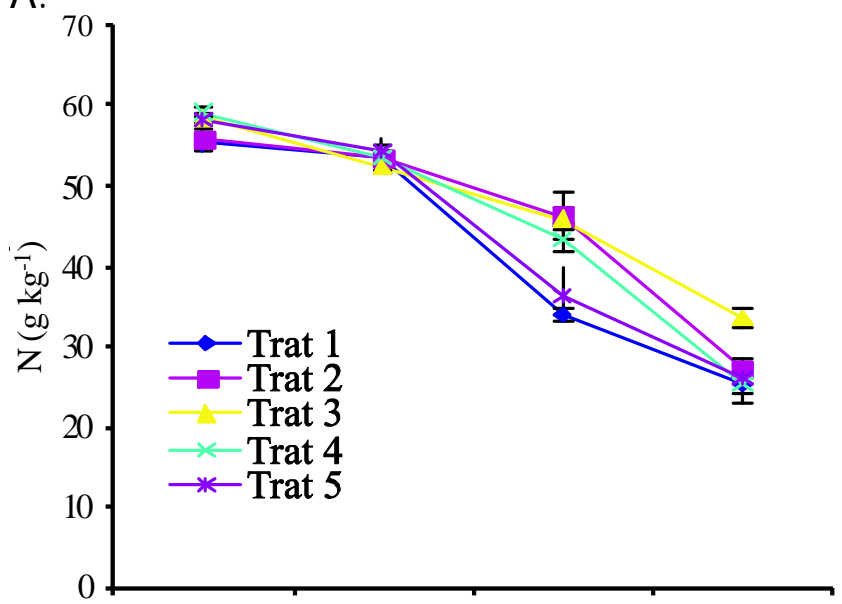

C.

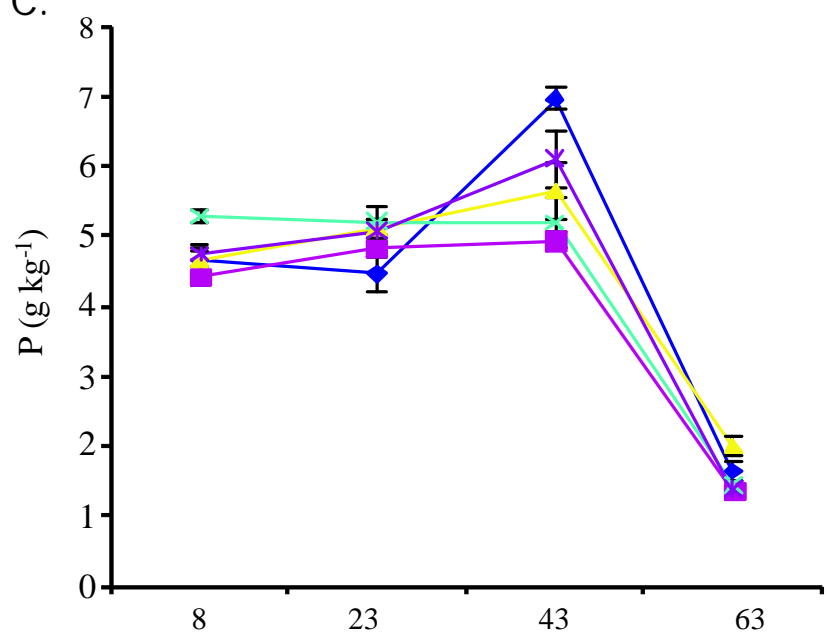

B.

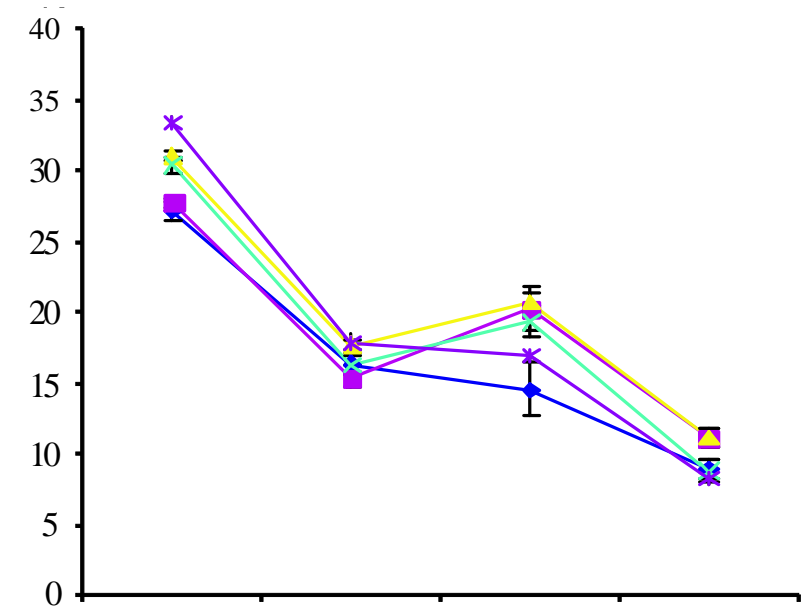

D.

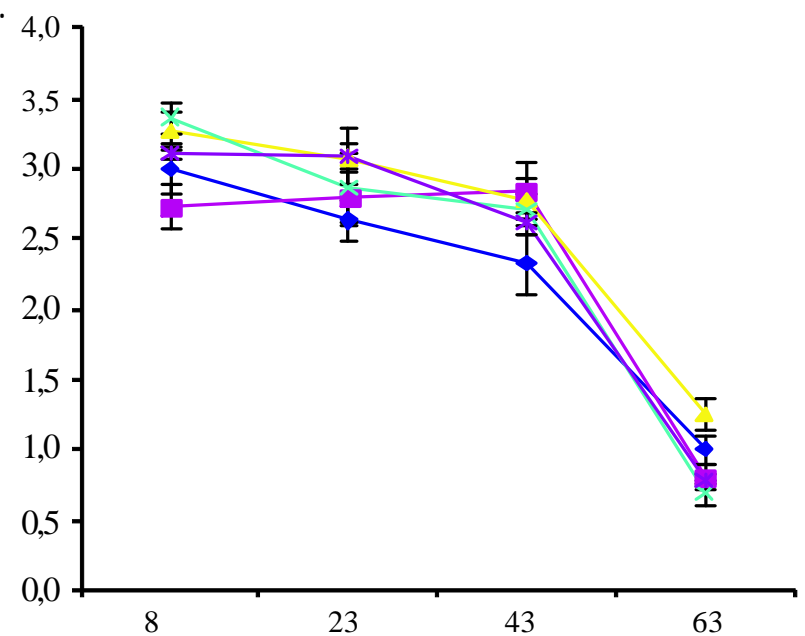

Dias após o plantio

Figura 5. Teores de $\mathrm{N}$ e $\mathrm{P}$ em folhas ( $\mathrm{A}$ e $\mathrm{C}$ ) e hastes ( $\mathrm{B}$ e $\mathrm{D}$ ) de plantas de feijão-de-corda, irrigadas com água salina em diferentes estádios de desenvolvimento. As barras representam o erro padrão da média. $n=5$

sultado semelhante ao encontrado por Sousa et al. (2007) e Assis Júnior et al. (2007), porém diferente do encontrado por Murillo-Amador et al. (2006); todavia, outros pesquisadores constataram que o estresse salino pode reduzir ou aumentar o teor de potássio nas folhas dessa espécie, sendo esta resposta dependente da variedade em estudo (Costa et al., 2003). De acordo com Lacerda (2005), a duração do estresse e a idade da folha amostrada podem, também, produzir diferentes resultados e interpretações, que podem estar relacionadas às diferenças entre os diversos tratamentos, no que diz respeito às taxas de re-translocação de $\mathrm{K}^{+}$na planta.

De modo geral, os teores de nitrogênio decresceram ao longo do ciclo em todos os tratamentos, tanto nas folhas como nas hastes (Figuras 5A e B), o que se deve, em parte, aos efeitos de diluição e à mobilização desse nutriente para as partes reprodutivas da planta. Ao final do ciclo, os teores de $\mathrm{N}$ foram maiores nas plantas do tratamento $\mathrm{T} 3$, fato explicado pelo retardo no seu crescimento e desenvolvimento. Os teores de nitrogênio variaram ao longo do ciclo da cultura porém os valores encontrados nas folhas sempre foram superiores ao nível considerado crítico para o feijão-de-corda (Melo et al., 2005).
Os teores de fósforo decresceram ao final do ciclo, tanto nas folhas como nos caules (Figura 5C e D), refletindo a translocação desse nutriente para a formação das sementes. Ao final do ciclo, os teores desse nutriente nas folhas foram maiores nas plantas do T3 sinal de que menos fósforo foi translocado para as vagens em função da menor quantidade de drenos reprodutivos produzidos por essas plantas. Os teores foliares de P estão acima do nível considerado ótimo para a cultura (Melo et al., 2005) reflexo, talvez, de adubações realizadas em cultivos anteriores na área em que foi realizado o experimento.

A irrigação com água salina ao longo de todo o ciclo (T2) não provocou aumento nos teores de $\mathrm{P}$ nas folhas (Figura 5C), resultado que diverge de outros estudos, ao se encontrar aumento nos teores foliares de $\mathrm{P}$ em plantas estressadas em comparação com plantas não estressadas (Lacerda, 2005); entretanto, o aumento na absorção e no acúmulo de $\mathrm{P}$ em plantas estressadas é mais comum quando as concentrações de P são altas na solução de cultivo (Navarro et al., 2001) e podem não ocorrer em plantas cultivadas no campo. Grattan \& Grieve (1999), também ressaltam que a interação entre salinidade e nutrição de fósforo em plantas é bastante complexa e altamen- 
te dependente da espécie vegetal ou cultivar, do estádio de desenvolvimento, da composição e concentração de sais e da própria concentração de P no meio de crescimento.

\section{CONCLUSÕES}

1. A aplicação de água salina durante todo o ciclo (T2) e durante a germinação e estádio inicial de crescimento (T3), em relação à aplicação de água do poço (controle), reduziu as taxas de fotossíntese e transpiração e as taxas de crescimento vegetativo e ainda provocou acúmulo especialmente de $\mathrm{Na}^{+}$e $\mathrm{Cl}^{-}$, porém nas plantas do $\mathrm{T} 3$ se verificou recuperação de todas essas variáveis ao final do ciclo da cultura.

2. As alterações no acúmulo de $\mathrm{Na}^{+}$e $\mathrm{Cl}^{-}$nas plantas dos tratamentos T4 e T5 não foram suficientes para provocar alterações significativas nas trocas gasosas nem nas taxas de crescimento da cultura, em comparação com as plantas do T1 (controle).

3. Os teores de minerais $\left(\mathrm{K}^{+}, \mathrm{Ca}^{2+}, \mathrm{Na}^{+}, \mathrm{Cl}^{-}, \mathrm{Ne} \mathrm{P}\right)$ variaram durante o desenvolvimento da cultura em função dos efeitos de diluição, da mobilização dentro da planta e das suas concentrações na água de irrigação.

\section{AGRADECIMENTOS}

Os autores agradecem ao Fundo Setorial CT-HIDRO e ao Conselho Nacional de Desenvolvimento Científico e Tecnológico, pelo suporte financeiro.

\section{LITERATURA CITADA}

Assis Júnior, J. O.; Lacerda, C. F. de; Silva, F. B.; Silva, F. L. B.; Bezerra, M. A; Gheyi, H. R. Produtividade do feijão-decorda e acúmulo de sais no solo em função da fração de lixiviação e da salinidade da água de irrigação. Engenharia Agrícola, v.27, n.3 p.702-713. 2007.

Ayers, R. S.; Wescot, D. W. A qualidade da água na agricultura. Campina Grande: UFPB, 1999.153p.

Benincasa, M. M. P. Análise de crescimento de plantas: Noções básicas. Jaboticabal: FUNEP. 1988. 42p.

Bezerra, M. A.; Lacerda, C. F. de; Prisco, J. T; Gomes Filho, E. Crescimento e fotossíntese de plantas jovens de cajueiro anão-precoce sob estresse salino. Revista Brasileira de Engenharia Agrícola e Ambiental, v.9, suplemento, p.90-94, 2005.

Bezerra, M. A.; Oliveira, R. A.; Lacerda, C. F. de; Prisco, J. T.; Gomes-Filho, E. Fotossíntese de plantas de cajueiro-anão precoce submetidas ao estresse salino. Proceedings of the Interamerican Society for Tropical Horticulture, v.47, p.149-152, 2003.

Chartzoulakis, K. S.; Loupassaki, M. H. Effects of $\mathrm{NaCl}$ salinity on germination, growth, gas exchange and yield of greehouse eggplant. Agricultural Water Management, v.32, n.3, p215-225, 1997.
Costa, P. H. A.; Silva, J. V.; Bezerra, M. A.; Enéas Filho, J.; Prisco, J. T.; Gomes Filho, E. Crescimento e níveis de solutos orgânicos e inorgânicos em cultivares de Vigna unguiculata submetidos à salinidade. Revista Brasileira de Botânica, v.26, n.3, p.289-297, 2003.

Dantas, J. P.; Marinho, F. J. L.; Ferreira, M. M. M.; Amorim, M. S. N.; Andrade, S. I. O.; Sales, A. L. Avaliação de genótipos de caupi sob salinidade. Revista Brasileira de Engenharia Agrícola e Ambiental, v.6, n.3, p.425-430. 2002.

Fernandes, V. L. B. Recomendações de adubação e calagem para o estado do Ceará. Fortaleza: UFC, 1993. 248p.

Gheyi, H. R.; Correia, K. G.; Fernandes, P. D. Salinidade do solo e crescimento e desenvolvimento das plantas. In: Nogueira, R. J. C.; Araújo, E. L.; Willadino, L. G.; Cavalcante, U. M. T. (ed.). Estresses ambientais: Danos e benefícios em plantas. Recife: UFRPE, 2005, p.138 -148.

Grattan, S. R.; Grieve, C. M. Salinity-mineral nutrient relations in horticultural crops. Scientia Horticulturae, v.78, p.127157, 1999.

Guimarães, F. V. Respostas fisiológicas e bioquímicas em plantas de feijão de corda cv Pitiúba submetidas ao estresse com $\mathrm{NaCl}$ em diferentes concentrações de $\mathrm{CaCl}_{2}$ e $\mathrm{CaSO}_{4}$. Fortaleza: UFC, 2005. 176p. Tese Doutorado

Kurban, H.; Saneoka, H.; Nehira, K.; Adilla, R.; Premachandra, G. S.; Fujita, K. Effect of salinity on growth, photosynthesis and mineral composition in leguminous plant Alhagi pseudoalhagi (Bieb.). Soil Science and Plant Nutrition, v.45, p.851-862. 1999.

Lacerda, C. F de. Interação salinidade x nutrição mineral. In: Nogueira, R. J. C.; Araújo, E. L.; Willadino, L. G.; Cavalcante, U. M. T. (ed.). Estresses ambientais: Danos e benefícios em plantas. Recife: UFRP, 2005. p.127-137.

Lacerda, C. F.; Assis Júnior, J. O.; Lemos Filho, L. C. A.; Guimarães, F. V. A.; Oliveira, T. S.; Gomes Filho, E.; Prisco, J. T.; Bezerra, M. A. Morpho-physiological responses of cowpea leaves to salt stress. Brazilian Journal Plant Physiology, v.18, n.4, p.455-465, 2006.

Malavolta, E.; Vitti, G. C.; Oliveira, S. A. Avaliação do estado nutricional das plantas: princípios e aplicações. 2.ed., Piracicaba: POTAFOS, 1997. 319p.

Marschner, H. Mineral nutrition of higher plants. 2.ed. London: Academic Press, 1995. 674p.

Melo, F. B.; Cardoso, M. J.; Salviano, A. A. C. Fertilidade do solo e adubação. In: Freire Filho, F. R.; Lima, J. A. A.; Ribeiro, V. Q. Feijão caupi: Avanços tecnológicos. Brasília: EMBRAPA, 2005. cap. 6, p.231-242.

Mendes, R. M. S.; Távora, F. J. A. F.; Pinho, J. L. N.; Pitombeiras, J. B. Alterações na relação fonte-dreno em feijão-de-corda submetido a diferentes densidades de plantas. Revista Ciência Agronômica, v36, n.1, p. 82-90, 2005.

Munns, R. Comparative physiology of salt and water stress. Plant and Cell Environment, v.25, n.2, p.239-250. 2002.

Murillo-Amador, B.; Diéguez, E. T.; Hernández, J. L. G.; Aguilar, R. L; Serrano, N. Y. A.; Salgado, S. Z.; Puente, E. O. R.; Kaya, C. Effect of $\mathrm{NaCl}$ salinity in the genotypic variation of cowpea (Vigna unguiculata) during early vegetative growth. Scientia Horticulturae, v.108, n.4, p.423-431. 2006. 
Navarro, J. M.; Botella, M. A.; Cerdá, A.; Martinez, V. Phosphorus uptake and translocation in salt-stressed melon plants. Journal of Plant Physiology, v.158, n.3, p.375-381. 2001.

Peyrano, G.; Taleisnik, E.; Quiroga, M.; Forchetti, S. M.; Tigier, H. Salinity effects on hydraulic conductance, lignin content and peroxidase activity in tomato roots. Plant Physiology and Biochemistry, v.35, p.387-393. 1997.

Rhoades, J. D.; Kandiah, A.; Mashali, A. M. Uso de águas salinas para produção agrícola. Campina Grande: UFPB, 2000. 117p. Estudos FAO. Irrigação e Drenagem, 48

Silva, J. V.; Lacerda, C. F. de; Costa, P. H.; Enéas Filho, J.; Gomes Filho, E.; Prisco, J. T. Physiological responses of $\mathrm{NaCl}$ stressed cowpea plants grown in nutrient solution supplemented whit $\mathrm{CaCl}_{2}$. Brazilian Journal of Plant Physiology, v.15, n.2, p.99-105. 2003.

Sousa, R. A.; Lacerda, C. F. de; Filho, J. A.; Hernandez, F. F. F. Crescimento e nutrição mineral do feijão-de-corda em função da salinidade e da composição iônica da água de irrigação. Revista Brasileira de Ciências Agrárias, v.2, n.1 p.75-82. 2007.
Souza, M. S. M.; Bezerra, F. M. L.; Teófilo, E. M. Coeficientes de cultura do feijão caupi na região litorânea do Ceará. Irriga, v.10, n.3, p.241-248. 2005.

Trindade, A. R.; Lacerda, C. F. de; Gomes Filho, E.; Bezerra, M. A.; Prisco, J. T. Influência do acúmulo e distribuição de íons sobre a aclimatação de plantas de sorgo e feijão-de-corda, ao estresse salino. Revista Brasileira de Engenharia Agrícola e Ambiental, v.10, n.4, p.804-810, 2006.

Wilson, C.; Liu, S.; Lesch, S. M.; Suarez, D. L. Growth response of major USA cowpea cultivars. I. Biomass accumulation and salt tolerance, HortScience, v.41 p.225-230. 2006a.

Wilson, C.; Liu, S.; Lesch, S. M.; Suarez, D. L. Growth response of major USA cowpea cultivars II. Effect of salinity on leaf gas exchange. Plant Science, v.170, n.6, p.10951101. 2006b.

Yeo, A. R. Predicting the interaction between the effects of salinity and climate change on crop plants. Scientia Horticulturae, v.78, n.1-4, p.159-174. 1999. 